\title{
A Comparative Validation Study of Fluconazole by HPLC and UPLC with Forced Degradation Study
}

\author{
Hetal Jebaliya, ${ }^{1}$ Madhavi Patel, ${ }^{1,2}$ Yashwant Jadeja, ${ }^{1}$ Batuk Dabhi, ${ }^{1}$ and Anamik Shah ${ }^{1}$ \\ ${ }^{1}$ Department of Chemistry, Saurashtra University, Rajkot, Gujarat 360005, India \\ ${ }^{2}$ Banasthali Vidyapith, P.O. BanasthaliVidyapith, Rajasthan 304022, India \\ Correspondence should be addressed to Anamik Shah; anamik_shah@yahoo.com
}

Received 18 September 2013; Accepted 27 October 2013

Academic Editor: Toyohide Takeuchi

Copyright (c) 2013 Hetal Jebaliya et al. This is an open access article distributed under the Creative Commons Attribution License, which permits unrestricted use, distribution, and reproduction in any medium, provided the original work is properly cited.

\begin{abstract}
The simplest stability indicating reversed phase Isocratic HPLC and UPLC methods has been developed and validated for the determination of fluconazole in bulk and solid pharmaceutical dosage form. A SunFire C18 $(250 \times 4.5 \mathrm{~mm}, 5 \mu \mathrm{m}$ particle size $)$ column has been used for HPLC and BEH C18 $(100 \times 2.1 \mathrm{~mm}, 1.7 \mu \mathrm{m}$ particle size $)$ column used for UPLC. The Mobile phase consisted of Methanol: Water $(70: 30)$ for HPLC and Methanol: Water $(55: 45 \mathrm{v} / \mathrm{v})$ for UPLC. Isocratic flow was set at $1 \mathrm{~mL} / \mathrm{min}$ and $0.30 \mathrm{~mL} / \mathrm{min}$, respectively, for HPLC and UPLC. For both HPLC and UPLC system detection has been performed at $211 \mathrm{~nm}$ with $30^{\circ} \mathrm{C}$ column oven temperature (good elution was obtained at $30^{\circ} \mathrm{C}$ ) and injection volume, respectively, $2 \mu \mathrm{L}$ and $20 \mu \mathrm{L}$ for HPLC and UPLC.
\end{abstract}

\section{Introduction}

Fluconazole [2-(2,4-difluorophenyl)-1,3-bis-(1H-1,2,4-triazole-1-yl)-2-propanol] [1] is mainly used as an antifungal antibiotic [2-4] (Figure 1) is and also used to prevent yeast infections in patients who are likely to become infected, because they are being treated with chemotherapy or radiation therapy before a bone marrow transplant. Several HPLC methods were reported for the analysis of fluconazole in pharmaceutical preparations and in body fluids as plasma, serum, and human urine sample $[1,5-11]$. Few of GC and HPLC methods have been reported for the determination of fluconazole in biological fluids, eye drops, and creams [12]. The UV method was also reported for syrups, capsules and intravenous solution, and microbiological assay for capsules [13]. Few of HPLC and UPLC methods have also been reported for the simultaneous determination of fluconazole and its combination dosage tablet $[14,15]$. LC-MS/MS method was also reported for the determination of fluconazole in human plasma [16]. Review literature suggested that there is no single UPLC method reported for the determination of fluconazole in pharmaceutical dosage forms or in API with acidic, alkali (Figure 5), oxidative (Figure 6), thermal (Figure 7), and photo degradation (Figure 8) study. Ultraperformance liquid chromatography (UPLC) (Figure 2) is well known and widely used analytical technique for the analysis of drug products and drug substance [17]. Current work has advantages over the earlier in terms of speed and simplicity. This work also deals with the stability indicating study and forced degradation of fluconazole under conditions such as oxidation, acid hydrolysis, base hydrolysis, and thermal and photolytic stress [18]. This method was validated using both the instruments HPLC and UPLC by different parameters such as linearity, accuracy, precision, robustness, solution stability, and forced degradation studies. The validation procedure followed the ICH (international conference on harmonization of technical requirements for registration of pharmaceuticals for human use) guidelines Q2A and Q2B $[19,20]$.

\section{Instrument}

The chromatographic HPLC system (Figure 3) was used to perform development and validation of this assay method consisted Waters 2489 equipped with UV/Visible detector, quaternary solvent manager pump, and $20 \mu \mathrm{L}$ manual injector loop. UPLC analysis was performed on Waters Acquity 


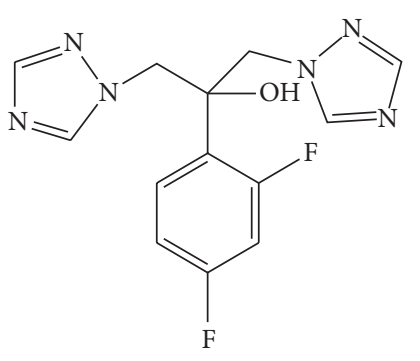

FIGURE 1: Structure of fluconazole.

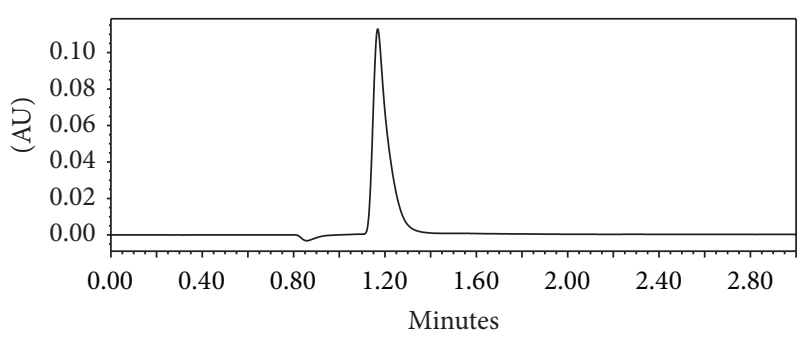

Figure 2: Fluconazole standard chromatogram using UPLC.

UPLCTH system which contains binary solvent manager, autoinjector with PDA detector. For data acquisition, Empower 2.0 version software is used for both instruments.

\section{Material}

Reference standard of fluconazole was provided by Symed labs limited Hyderabad, India, and tablets of fluconazole $(100 \mathrm{mg})$ were purchased from market. HPLC grade acetonitrile and methanol were purchased from Merc India Limited, Mumbai, India. Analytical grade hydrochloric acid, sodium hydroxide pellets, and hydrogen peroxide were purchased from Ranbaxy fine chemicals, New Delhi, India. High purity deionised water was obtained from Milli-Q (Millipore, Miliford, MA, USA) purification system. $0.45 \mu \mathrm{m}$ membrane filters were purchased from Pall Life sciences, Mumbai, India, and nylon syringe filters $0.45 \mu \mathrm{m}$ were purchased from Millex-Hn, Mumbai, India.

\section{Chromatographic Condition}

The chromatographic analysis has been performed on SunFire C18 $(250 \times 4.5 \mathrm{~mm}$ id, $5 \mu \mathrm{m}$ particle size $)$ and Acquity UPLC @BEH C18 $(100 \times 2.1 \mathrm{~mm}$ id, $1.7 \mu \mathrm{m}$ particle size $)$ columns simultaneous for HPLC and UPLC. The HPLC mobile phase were consisted of Methanol : Water $(70: 30)$ and for UPLC it consisted of Methanol: Water $(55: 45 \mathrm{v} / \mathrm{v})$ with $211 \mathrm{~nm} \mathrm{UV}$ detection and $30^{\circ} \mathrm{C}$ column oven temperature. HPLC flow rate was adjusted at $1 \mathrm{~mL} / \mathrm{min}$ with $20 \mu \mathrm{L}$ injection volume and for UPLC it was adjusted at $0.3 \mathrm{~mL} / \mathrm{min}$ with $2 \mu \mathrm{L}$ injection volume. The total analysis time was selected 7.0 minute for HPLC and 3.0 minute for UPLC.

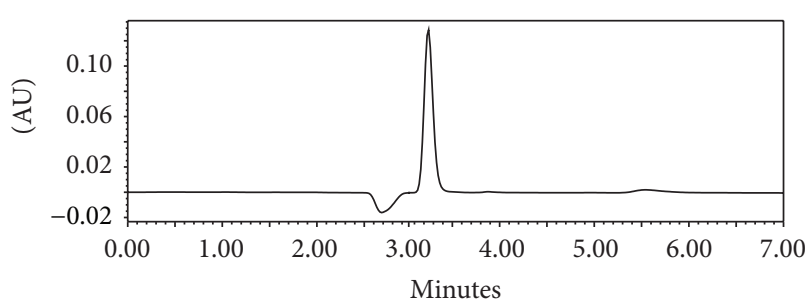

FIGURE 3: Fluconazole standard chromatogram using HPLC.

\section{Preparation of Standard Solution}

The stock solution of fluconazole was prepared by dissolving accurately weighted $25 \mathrm{mg}$ of fluconazole in $50 \mathrm{~mL}$ volumetric flask with diluent (Water: Methanol $(50: 50))$. This stock solution contains $500 \mu \mathrm{g} / \mathrm{mL}$ fluconazole. For standard preparation take $5 \mathrm{~mL}$ of above stock solution in $50 \mathrm{~mL}$ volumetric flask and dilute it with diluent. These standard solutions contain $50 \mu \mathrm{g} / \mathrm{mL}$ fluconazole.

\section{Preparation of Sample Solution}

The preparation of $500 \mu \mathrm{g} / \mathrm{mL}$ stock solution: twenty tablets were accurately crushed and weighted and average weight has been calculated. The portion of powder equivalent to the weight of one tablet has been taken and transferred to a $50 \mathrm{~mL}$ volumetric flask and diluted up to the mark with diluents and filtered through $0.45 \mu \mathrm{m}$ membrane filter. For sample preparation $5 \mathrm{~mL}$ of stock solution was pipette out and transfer in $50 \mathrm{~mL}$ volumetric flask, diluted to volume with diluent. This solution was containing $50 \mu \mathrm{g} / \mathrm{mL}$ fluconazole.

\section{Result and Discussion}

7.1. Method Optimization. Several trials have been taken for accurate and precise method development. After using different buffers and columns, suitable column chemistry and good peak shape was obtained only in HPLC SunFire C18 $(250 \times 4.5 \mathrm{~mm}$ id, $5 \mu \mathrm{m}$ particle size $)$ and Acquity UPLC @ BEH C18 $(100 \times 2.1 \mathrm{~mm}$ id, $1.7 \mu \mathrm{m}$ particle size $)$ columns with Isocratic mobile phase which contained Methanol: Water $(70: 30)$ and $(55: 45 \mathrm{v} / \mathrm{v})$ simultaneous for HPLC and UPLC. For wavelength selection the standard solution was screened over 190-400 nm using the advantage of photo diode array detector. On the basis of peak absorption maxima and peak purity index, the $211 \mathrm{~nm}$ was decided as the detection wavelength which provided the maximum chromatographic compatibility to the method.

7.2. Method Validation. Method validation includes several parameters like accuracy, precision, linearity, robustness, specificity, degradation study, limit of detection (LOD), and limit of quantification (LOQ). These all validation parameters have been performed systematically on both HPLC and UPLC instruments. All validations have been performed as per ICH guidelines Q2A and Q2B [19, 20]. 
TABlE 1: Degradation of analyte applying forced degradation.

\begin{tabular}{lccccc}
\hline Stress condition & Acidic & Alkali & Oxidative & Thermal & Photolytic \\
\hline$\%$ degradation & $96.44 \%$ & $96.74 \%$ & $85.83 \%$ & $89.43 \%$ & $96.78 \%$ \\
\hline
\end{tabular}

TABLE 2: Robustness study data obtained from HPLC.

\begin{tabular}{|c|c|c|c|c|c|}
\hline \multicolumn{2}{|c|}{ Robustness conditions } & \multirow{2}{*}{$\mathrm{RT}(\min )$} & \multirow{2}{*}{ ASSAY (\%) } & \multicolumn{2}{|c|}{ System suitability data } \\
\hline Type & Rate & & & Theoretical plate & Asymmetry \\
\hline \multirow{2}{*}{ Flow rate } & $0.9 \mathrm{~mL} / \mathrm{min}$ & 3.59 & 100.09 & 3498 & 0.97 \\
\hline & $1.1 \mathrm{~mL} / \mathrm{min}$ & 2.95 & 99.84 & 3607 & 1.03 \\
\hline \multirow{2}{*}{ Temperature } & $28^{\circ} \mathrm{C}$ & 3.24 & 98.97 & 3930 & 1.07 \\
\hline & $32^{\circ} \mathrm{C}$ & 3.22 & 99.68 & 3890 & 1.50 \\
\hline \multirow{2}{*}{ Mobile phase } & $72: 28$ & 3.16 & 101.07 & 4027 & 1.67 \\
\hline & $68: 32$ & 3.32 & 99.42 & 4145 & 1.09 \\
\hline
\end{tabular}

Accuracy study was performed on the basis of recovery study at three levels $50 \%, 100 \%$, and $150 \%$ of sample concentration. The recovery was found between 99 and 100\% for both HPLC and UPLC, which is between under the acceptance criteria of ICH guideline Q2(A) [19].

Precision study has been performed by multiple preparations of a single sample. Six different preparations of fluconazole were analysed in triplicate on the same day. Fresh solutions was prepared and analysed for system precision and method precision study. The $\%$ assay value has been calculated for each sample preparation using the peak area of chromatogram. The relative standard deviation obtained from the assay value of fluconazole using HPLC and UPLC has not more than $2 \%$.

Linearity study was evaluating by analyzing seven solutions in the concentration range between $40,60,80,100$, 120,140 , and $160 \%$ which contain $20,30,40,50,60,70$, and $80 \mu \mathrm{g} / \mathrm{mL}$ fluconazole, respectively. Linear regression equation was calculated by peak area obtained from different concentrations. It was $y=2907 x+6956$ for HPLC and $y=$ $89810 x+95164$ for UPLC. The Correlation coefficient $\left(R^{2}\right)$ was found to be 0.984 and 0.998 , respectively, for HPLC and UPLC.

The Limit of detection (LOD) and Limit of Quantification (LOQ) have been established by evaluating the minimum level at which the analyte could be readily detected and quantified accurately. The LOD and LOQ were found at 0.5 and $1.5 \mu \mathrm{g} / \mathrm{mL}$ for HPLC while for UPLC it was found at 0.3 and $1.4 \mu \mathrm{g} / \mathrm{mL}$ concentration level. It can be calculated as per the following equation:

$$
\begin{aligned}
\mathrm{LOD}=3.3\left(\frac{\mathrm{SD}}{S}\right), & \mathrm{LOQ}=10\left(\frac{\mathrm{SD}}{S}\right), \\
\mathrm{LOD}=0.5 \mu \mathrm{g} / \mathrm{mL} \quad(\mathrm{HPLC}), & \mathrm{LOQ}=1.5 \mu \mathrm{g} / \mathrm{mL} \quad(\mathrm{HPLC}), \\
\mathrm{LOD}=0.3 \mu \mathrm{g} / \mathrm{mL} \quad(\mathrm{UPLC}), & \mathrm{LOQ}=1.4 \mu \mathrm{g} / \mathrm{mL} \quad(\mathrm{UPLC}),
\end{aligned}
$$

where SD is standard deviation of the response and $S$ is slope of the calibration curve.

The specificity of the method has been evaluated by ensuring that there was no interference from the placebo

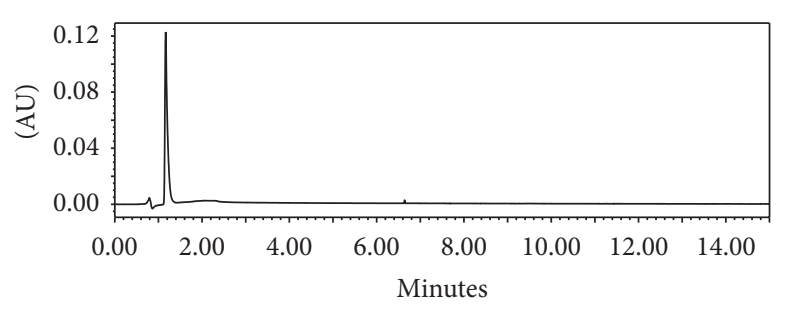

FIgURE 4: Chromatogram of acid degradation.

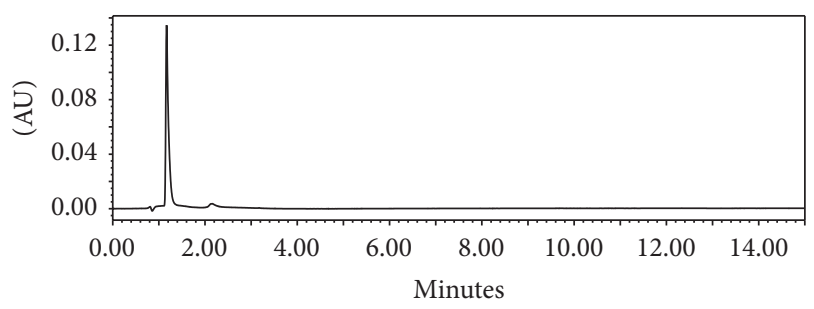

FIGURE 5: Chromatogram of base degradation.

components or from products resulting from forced degradation.

The degradation study was performed by applying acidic, alkali, oxidative, thermal, and sunlight stress to the sample and further the degradation was investigated using the above chromatographic method. The degradation study ensures that the method was able to separate fluconazole from the probable degradation products generated during the forced degradation study. Acid degradation (Figure 4) of the drug was performed by heating the drug with $1 \mathrm{~N} \mathrm{HCl}$ for 45 minutes at $80^{\circ} \mathrm{C}$. Alkaline degradation was performed by heating the drug with $0.1 \mathrm{M} \mathrm{NaOH}$ for 60 minutes at $80^{\circ} \mathrm{C}$. Oxidizing degradation was performed by heating the drug with $3 \%$ $\mathrm{H}_{2} \mathrm{O}_{2}$ at $80^{\circ} \mathrm{C}$ for 60 minutes. Thermal degradation was performed by exposing solid drug at $80^{\circ} \mathrm{C}$ for $24 \mathrm{hrs}$ in hot air oven. For photolytic degradation powder drug has been exposed to sunlight for $36 \mathrm{hrs}$ (day hrs only). The placebo was also subjected to the same stress conditions to identify any response due to the forced degradation conditions. 
TABLE 3: Robustness study data obtained from UPLC analysis.

\begin{tabular}{|c|c|c|c|c|c|}
\hline \multicolumn{2}{|c|}{ Robustness conditions } & \multirow{2}{*}{$\mathrm{RT}(\min )$} & \multirow{2}{*}{ ASSAY (\%) } & \multicolumn{2}{|c|}{ System suitability data } \\
\hline Type & Rate & & & Theoretical plate & Asymmetry \\
\hline \multirow{2}{*}{ Flow rate } & $0.28 \mathrm{~mL} / \mathrm{min}$ & 1.25 & 99.85 & 2792 & 1.06 \\
\hline & $0.32 \mathrm{~mL} / \mathrm{min}$ & 1.06 & 101.99 & 2460 & 0.71 \\
\hline \multirow{2}{*}{ Temperature } & 28 & 1.05 & 98.95 & 2361 & 0.97 \\
\hline & 32 & 1.24 & 99.55 & 3194 & 1.67 \\
\hline \multirow{2}{*}{ Mobile phase } & $53: 47$ & 1.26 & 98.60 & 2984 & 1.05 \\
\hline & $57: 43$ & 1.11 & 99.51 & 2789 & 1.10 \\
\hline
\end{tabular}

TABLE 4: Comparison of HPLC and UPLC methods by validation results.

\begin{tabular}{lcc}
\hline Validation parameter & HPLC method & UPLC method \\
\hline Accuracy (\% Recovery) & $99-100$ & $99-100$ \\
Linearity & $y=2907 x+6956$ & $y 9810 x+95164$ \\
$\quad$ Regression equation & 0.984 & 0.998 \\
$\quad$ Corelation coefficient $\left(R^{2}\right)$ & & $(\% \mathrm{RSD}) 1.18$ \\
Precision & $(\% \mathrm{RSD}) 0.61$ & $(\% \mathrm{RSD}) 0.70$ \\
$\quad$ Intermediate precision & $(\% \mathrm{RSD}) 0.71$ & Highly robustness method \\
$\quad$ Method precision & Highly robustness method & No interference found to \\
Robustness & No interference found to & analyte peak \\
Specificity & analyte peak & $0.3 \mu \mathrm{g} / \mathrm{mL}$ \\
Limit of detection & $0.5 \mu \mathrm{g} / \mathrm{mL}$ & $1.4 \mu \mathrm{g} / \mathrm{mL}$ \\
Limit of quantification & $1.5 \mu \mathrm{g} / \mathrm{mL}$ & $3 \mathrm{minutes}$ \\
Total analysis time & 7 minutes & \\
\hline
\end{tabular}

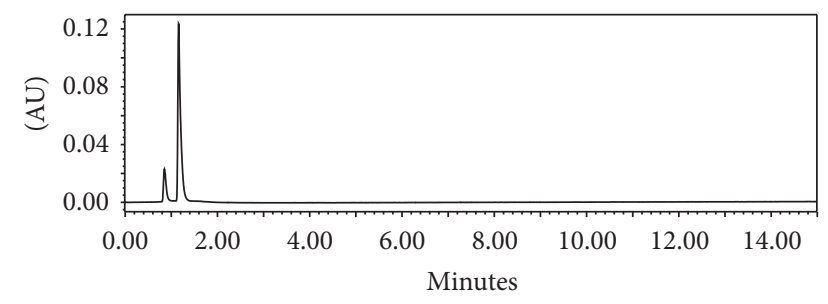

FIGURE 6: Chromatogram of oxidative degradation.

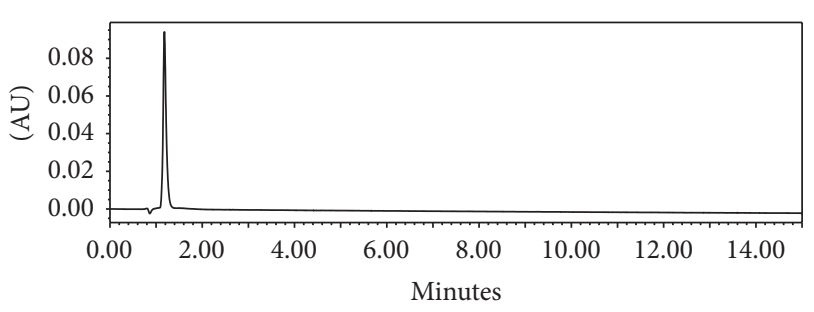

Figure 7: Chromatogram of thermal degradation.

After applying all these conditions the solutions were left in room temperature and diluted with diluent to furnish the volume up to the mark to prepare $50 \mu \mathrm{g} / \mathrm{mL}$ solution. The $\%$ degradation determined by the method was shown in Table 1 .

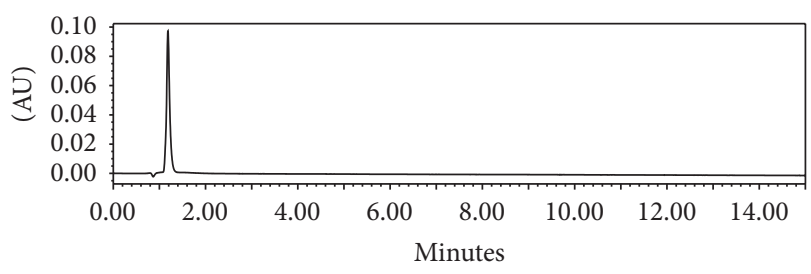

FIGURE 8: Chromatogram of photo degradation.

The robustness study was performed for proving that the method remained unaffected after slight but deliberate changes in the analytical conditions. Some factors chosen for this study were flow rate, mobile phase composition, and column oven temperature changes. The resulting data determined by this study was shown in Tables 2 and 3 .

The proposed HPLC and UPLC methods show a good sensitive, resolution and selectivity in bulk drug as well as in pharmaceutical dosage form. There was no significance observed on the results during analysis; therefore these both methods were highly robust, selective, precise, sensitive, and linear which was proven by the results obtained from validation study. The UPLC method was faster than HPLC method as it has only 3.0-minute analysis time and also the sensitivity was much higher as compared to HPLC method which is proven by comparison of validation results (Table 4). These both methods can be applicable for quantification of 
fluconazole in both drug substance and drug product in pharmaceutical dosage form.

\section{Acknowledgments}

The authors are grateful to the Department of Chemistry, Saurashtra University (UGC-SAP sponsored and DST-FIST funded), Rajkot, Gujarat, India. And also special thanks is to the "National Facility for Drug Discovery through NCE's development and Instrumentation support for small Manufacturing Pharma Entities" program under the Drug and Pharma Research Support (DPRS) jointly funded by Department of Science and Technology, New Delhi, Government of Gujarat Industries Commissionerate and Saurashtra University Rajkot for providing the Instrumental facilities. They are highly thankful to UGC, Govt. of India for providing financial support in terms of meritorious research fellowship.

\section{References}

[1] K. B. Liew, G. O. K. Loh, Y. T. F. Tan, and K. K. Peh, "Development and application of simple HPLC-Uv method for fluconazole quantification in human plasma," International Journal of Pharmacy and Pharmaceutical Sciences, vol. 4, no. 4, pp. 107111, 2012.

[2] N. M. Aloudah, M. A. Radwan, N. F. Al Omar, and S. Jacobs, "HPLC assay of fluconazole and its application to patients with early septic shock," Journal of Liquid Chromatography \& Related Technologies, vol. 28, no. 4, pp. 571-580, 2005.

[3] U. K. Sarker, M. Misbahuddin, and M. A. Hossain, "Bioequivalence study of Flunac and Diflucan in healthy Bangladeshi male volunteers," KYAMC Journal, vol. 2, no. 2, pp. 159-163, 2012.

[4] G. Naveen Kumar Reddy, V. V. S. Rajendra Prasad, N. Devanna, and P. K. Maharana, "Development and validation of a stability indicating uplc method for determination of voriconazole in pharmaceutical formulation," Der Pharmacia Lettre, vol. 3, no. 5, pp. 249-259, 2011.

[5] C. E. M. de Sousa, D. C. G. Bedor, L. C. A. Sampaio Filho et al., "High-performance liquid chromatographic determination of fluconazole in plasma and its application to a bioequivalence study," Latin American Journal of Pharmacy, vol. 30, no. 7, pp. 1432-1436, 2011.

[6] S.-S. Kim, H.-T. Im, I.-M. Kang et al., "An optimized analytical method of fluconazole in human plasma by high-performance liquid chromatography with ultraviolet detection and its application to a bioequivalence study," Journal of Chromatography $B$, vol. 852, no. 1-2, pp. 174-179, 2007.

[7] S. A. Dgither, A. Yusuf, and M. M. Hammami, "Fluconazole: stability and analysis in human plasma by simple high performance liquid chromatography," Fabad Journal of Pharmaceutical Sciences, vol. 34, no. 4, pp. 179-186, 2009.

[8] F. Al-Rimawi, "Development and validation of analytical method for fluconazole and fluconazole related compounds (A, $B$, and C) in capsule formulations by HPLC with UV detection," Jordan Journal of Chemistry, vol. 4, no. 4, pp. 357-365, 2009.

[9] J. W. Hülsewede and H. Dermoumi, "Serum level determination of fluconazole by high-performance liquid chromatography and bioassay," Zentralblatt für Bakteriologie, vol. 283, no. 4, pp. 492496, 1996.

[10] D. Hermawan, N. A. Md Ali, W. A. Wan Ibrahim, and M. M. Sanagi, "Analysis of fluconazole in human urine sample by high performance liquid chromatography method," Journal of Physics: Conference Series, vol. 423, Article ID 012009, 2013.

[11] S. R. C. J. Santos, E. V. Campos, C. Sanches, D. S. Gomez, and M. C. Ferreira, "Fluconazole plasma concentration measurement by liquid chromatography for drug monitoring of burn patients," Clinics, vol. 65, no. 2, pp. 237-243, 2010.

[12] A. B. Rege, J. Y. Walker-Cador, R. A. Clark, J. J. L. Lertora, N. E. Hyslop Jr., and W. J. George, "Rapid and sensitive assay for fluconazole which uses gas chromatography with electron capture detection," Antimicrobial Agents and Chemotherapy, vol. 36, no. 3, pp. 647-650, 1992.

[13] P. Sadasivudu, N. Shastri, and M. Sadanandam, "Development and validation of RP-HPLC and UV methods of analysis for fluconazole in pharmaceutical solid dosage forms," International Journal of ChemTech Research, vol. 1, no. 4, pp. 1131-1136, 2009.

[14] H. M. Lotfy, A. A. A. B. Abdel-Aleem, and H. H. Monir, "Stability-indicating high performance liquid chromatographic determination of fluconazole in the presence of its oxidative degradation product-kinetic and stress study," Journal of Liquid Chromatography and Related Technologies, vol. 36, no. 8, pp. 1013-1029, 2013.

[15] D. B. Meshram, S. B. Bagade, and M. R. Tajne, "Simple HPLC method for simultaneous estimation of fluconazole and tinidazole in combined dose tablet," Journal of Chromatographic Science, vol. 47, no. 10, pp. 885-888, 2009.

[16] D. Wu, K. C. Wade, D. J. Paul, and J. S. Barrett, "A rapid and sensitive LC-MS/MS method for determination of fluconazole in human plasma and its application in infants with candida infections," Therapeutic Drug Monitoring, vol. 31, no. 6, pp. 703709, 2009.

[17] B. Dabhi, Y. Jadeja, M. Patel, H. Jebaliya, D. Karia, and A. Shah, "Method development and validation of a stabilityindicating RP-HPLC method for the quantitative analysis of dronedarone hydrochloride in pharmaceutical tablets," Scientia Pharmaceutica, vol. 81, no. 1, pp. 115-122, 2013.

[18] R. Yanamandra, A. Chaudhary, S. R. Bandaru et al., "Development of a RP-UPLC method for the simultaneous analysis of secnidazole, fluconazole, and azithromycin: application in pharmaceuticals and human serum," International Journal of PharmTech Research, vol. 3, no. 2, pp. 1198-1207, 2011.

[19] International Conference on Harmonization (ICH) of Technical Requirements for the Registration of Pharmaceuticals for Human Use, Validation of Analytical Procedures: Definitions and Terminology, Q2A, Geneva, Switzerland, 1996.

[20] International Conference on Harmonization (ICH) of Technical Requirements for the Registration of Pharmaceuticals for Human Use, Validation of Analytical Procedures: Methodology, Q2B, Pharmaceutical Technology, Geneva, Switzerland, 1996. 

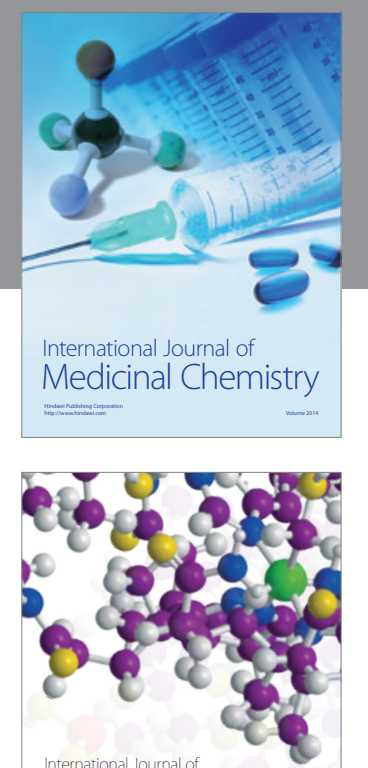

\section{Carbohydrate} Chemistry

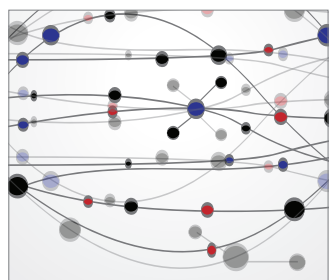

The Scientific World Journal
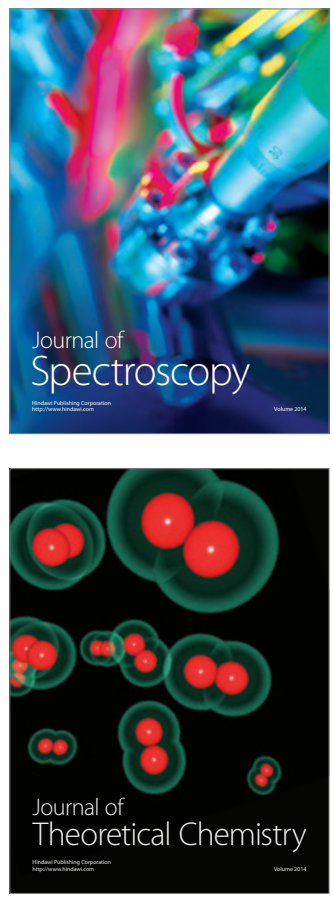
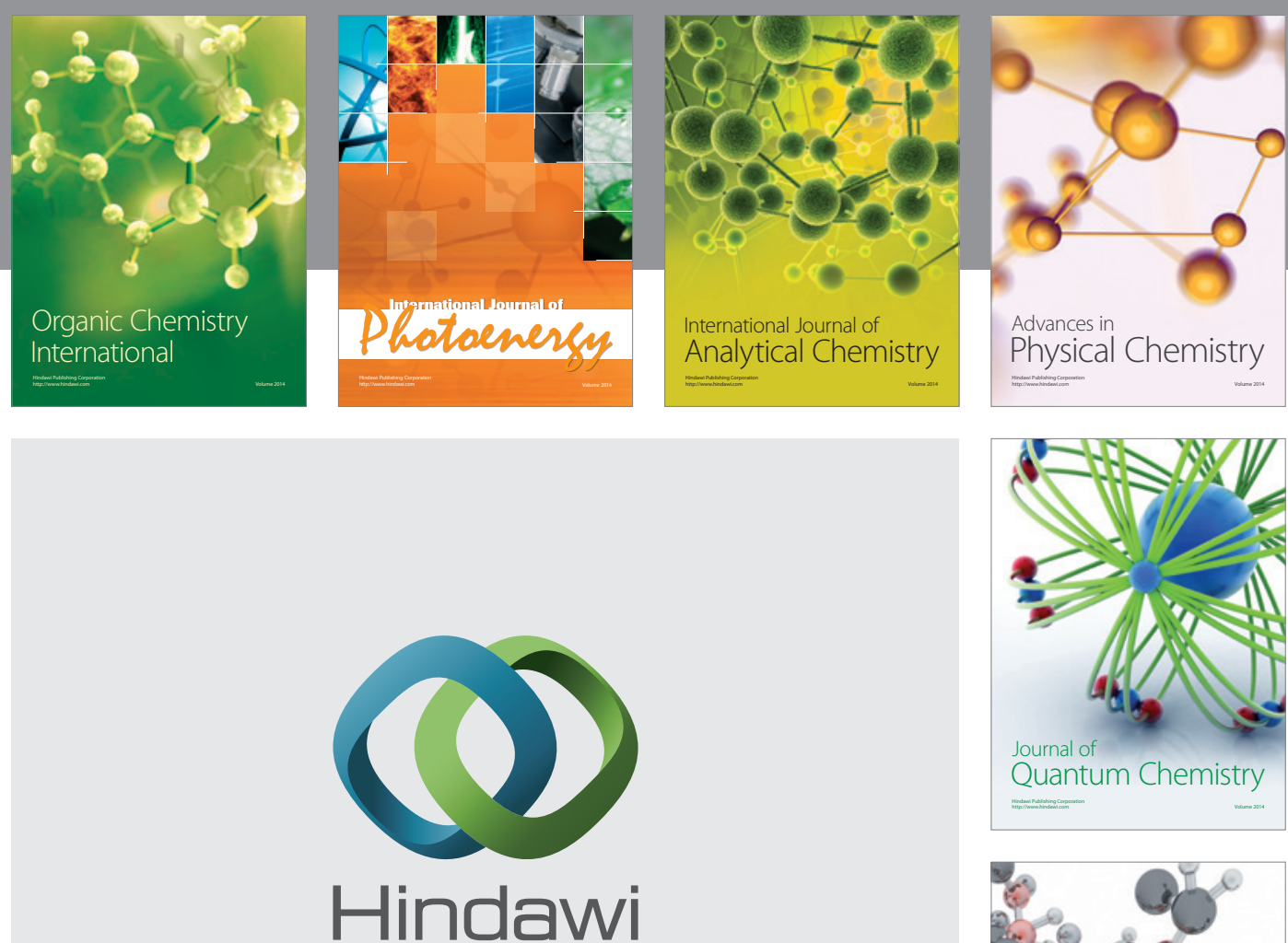

Submit your manuscripts at

http://www.hindawi.com

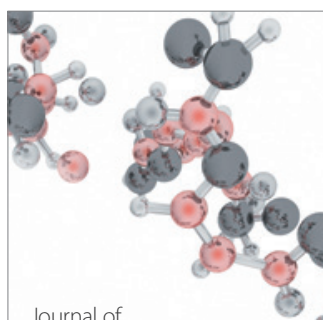

Analytical Methods

in Chemistry

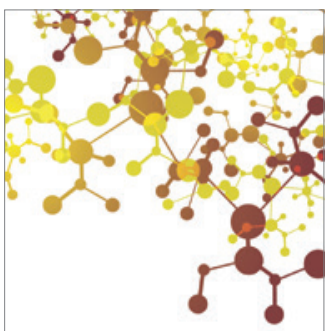

Journal of

Applied Chemistry

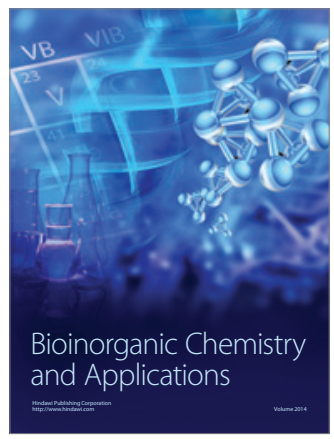

Inorganic Chemistry
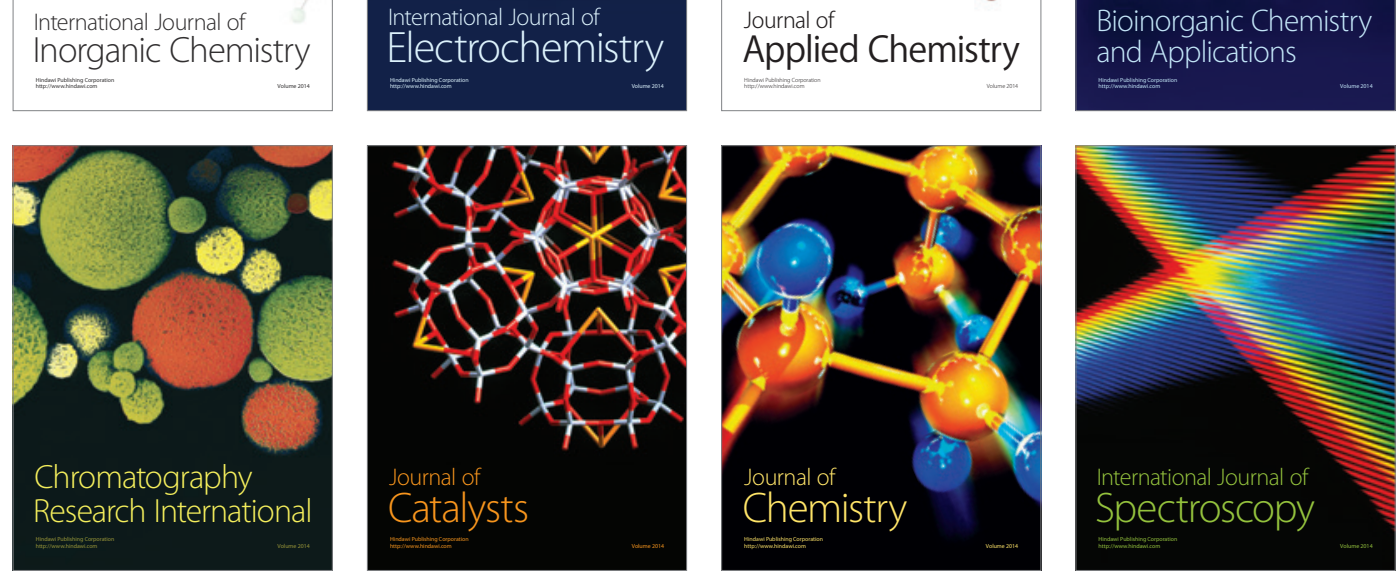